\title{
Evaluation of Laparoscopic Management of Incarcerated Congenital Inguinal Hernia
}

\author{
MAHMOUD E. BADAWY, M.D.; HISHAM A. ALMETAHER, M.D.; ABDEL MOTTALEB E. EBEID, M.D.; \\ MOHAMED A. SHEHATA, M.D. and ESSAM A. ELHALABY, M.D.
}

The Department of Surgery, Pediatric Surgery Unit, Faculty of Medicine, Tanta University

\begin{abstract}
Background: The laparoscopic management of incarcerated congenital inguinal Hernia in children is challenging and may be not devoid of risk. Controversies are still present about its management. Some surgeons prefer immediate repair as emergency even for successfully reduced hernias, others delay the repair for some days.

Aim of Study: The aim of this work is to evaluate the safety and efficacy of emergency laparoscopic management of incarcerated congenital inguinal hernia in children.

Methods: Eleven patients underwent emergency laparoscopic repair of incarcerated inguinal hernia using burse string sutures around internal inguinal ring.

Results: From August 2017 to January 2019, 11 patients were operated ( 9 males and 2 females) with a mean age of $8.81 \pm 4.26$ month. 8 right-sided and 3 left-sided hernias. Two patients with contralateral PPV were diagnosed and operated. All hernias were successfully reduced. The hernia content was: Bowel loops $8(73 \%)$, adnexa/ovary $2(18 \%)$, and appendix $1(9 \%)$. The mean operative time was $37.73 \pm 6.17$ minutes. There were no serious complications except that one patient had port site infection and another patient had ipsilateral hydrocele. No recurrence occurred during the follow-up period.

Conclusion: Emergency laparoscopic repair of congenital inguinal hernia provide an alternative procedure in pediatric patients presenting with incarcerated hernia. It appears to be feasible, safe and effective with few complications.
\end{abstract}

Key Words: Laparoscopic - Congenital inguinal herniaIncarceration.

\section{Introduction}

CONGENITAL inguinal hernia remains the most common surgical condition in pediatric patients. Incarcerated hernias are emergency problems and

Correspondence to: Dr. Mahmoud E. Badawy, The Department of Surgery, Pediatric Surgery Unit, Faculty of Medicine, Tanta University represent nearly $5-10 \%$ of all cases $[1-4]$. The standard emergency open approach can solve the problem after manual reduction of its contents; However, the operation is usually delayed after a successful reduction to avoid dissection through the edematous cord structures [5]. The traditional open inguinal repair has a recurrence rate of 0.2$1 \%$ in infants, increasing to $2-3 \%$ in the first year of life, and reach to $15-20 \%$ if the hernia is incarcerated $[6-8]$. There are many studies on laparoscopic repair of congenital hernia in infants and children [7,9]. However, few studies only on the laparoscopic management of incarcerated inguinal hernias have been published [10,11]. Controversies are still present about the management of the successfully reduced incarcerated inguinal hernia, few reports prefer immediate urgent operation even if the reduction was succeeded for fear of reincarceraion $[\mathbf{1 2 , 1 3 ]}$. Other surgeons delay surgery for 3 to 7 days because they think that, incarceration is rare within that period and to allow the tissue edema to be resolved $[\mathbf{1 4}, \mathbf{1 5}]$. The aim of this study is to evaluate the safety and efficacy of emergency laparoscopic management of incarcerated congenital inguinal hernia in children.

\section{Patients and Methods}

This was a prospective study conducted on patients with incarcerated congenital inguinal hernia Fig. (1) admitted to the Pediatric Surgery Unit, Tanta University Hospitals, (Egypt) during the period from August 2017 to January 2019. The study was approved by the Ethical Committee of Tanta Faculty of Medicine and informed consent was obtained from patients guardians. Neonates, prematures and neglected patients with bad general condition were excluded from the study. All patients 
were subjected to full history taking, clinical examination and urgent ultrasound examination to confirm the diagnosis, viability of the contents and check the contralateral internal ring. Once the diagnosis was confirmed, emergency laparoscopic interference was done.

Under general anesthesia, the patient was placed supine in the trendelenburg position with a 15 degree tilt. The laparoscopic monitor was placed at the patient's feet. The surgeon stood at the head of the patient in infants and at the other side of hernia in older children. The camera operator stood at the other side of hernia.

Insufflation of the abdomen through umbilical incision using open technique to guard against injury of distended intestine and a Pneumoperitoneum was established at a pressure $6-10 \mathrm{mmHg}$ according to the age. Three ports technique was used; $5 \mathrm{~mm}$ transumbilical port for 30 degree telescope. Another two $3-5 \mathrm{~mm}$ ports were inserted to the right and left side of the umbilicus according to age of patient Fig. (2). Laparoscopic exploration of the pelvis was done to examine the contralateral side. Reduction under direct vision was attempted by internal pulling using bowel forceps aided by external manual pressure. After reduction of the contents, the hernia orifice was closed circumferentially with purse string suture Fig. (6). Repair of the contralateral side was done if patent processus vaginalis was confirmed. Finally closure of the port sites after gradual deflation of the abdomen.

All patients were admitted to the pediatric surgical wards on the intravenous fluids and medications. Oral feeding was started after regaining of bowel movements. Discharge of the patient from the hospital after reaching full feeding. Antibiotics and oral analgesics as paracetamol were prescribed on demand.

All patients were followed-up weekly in the first month then every one month for 6 months clinically and by using doppler ultrasound examination of inguinoscrotal area in males and to detect testicular size and recurrence.

\section{Results}

This study includes 11 cases underwent emergency laparoscopic repair within 1 to 1.5 hour from admission. It included 9 males and 2 females with a mean age of $8.81 \pm 4.26$ month (range, 4 to 18 months). Weight of patients was ranged between 6 to $10.5 \mathrm{Kg}$ with a mean $8 \pm 1.49 \mathrm{Kg}$. There were 8 right-sided and 3 left-sided inguinal hernias. Two cases $(18 \%)$ had contralateral reducible congenital inguinal hernia diagnosed by preoperative ultrasound and was confirmed during laparoscopy and were managed laparoscopically at the same setting. Two patients (one male and one female) were reduced spontaneously during induction of general anesthesia and nine patients were reduced during the operation after insufflation of the abdomen aided by slight external compression. The hernia content was: Bowel loops 8 (73\%) Fig. (3), adnexa/ovary 2 (18\%) Fig. (4), and appendix 1 (9\%) Fig. (5). None of the patients needed bowel resection as the reduced congested segments improved after the bowel was returned to the peritoneal cavity. The ovaries were congested with no signs of ischemia. The mean operative time was $37.73 \pm$ 6. 17 minutes (range, 25 to $40 \mathrm{~min}$ ) from the start of abdominal insufflation till the end of internal ring repair, with only one case was converted from laparoscopic to open repair after reduction the of the contents as the bowel was hugely distended obscuring the field of vision and making the internal ring repair very difficult. No intra operative complications occurred during this study. Nine cases tolerated oral feeding after 6 to 10 hours except 2 cases suffered from abdominal distention which improved within 72 hours. Nine cases were discharged from the hospital one day after the operation and only 2 cases discharged after 3 days due to bowel congestion and intolerance to oral feeding. There was one case with post-operative port site infection successfully managed with antibiotics and daily dressing. One case (9.1\%) suffered from mild ipsilateral hydrocele which improved by conservative management. There were no cases with scrotal hematoma, testicular atrophy or recurrence noticed in the follow-up period which extended to 6 months.

Table (1): Patient's demographics and characteristics.

\begin{tabular}{lll}
\hline & Variable (n 11) & Mean \\
\hline Sex: & & \\
$\quad$ Male & 9 & \\
$\quad$ Female & 2 & \\
Site: & & \\
$\quad$ Right & 8 & \\
$\quad$ Left & 3 & $8.81 \pm 4.26$ month \\
Age & 4 to 18 months & \\
Weight & $6-10.5 \mathrm{Kg}$ & \\
Contents: & & \\
$\quad$ Bowel & 8 & \\
$\quad$ Adnexa/ovary & 2 & $37.73 \pm 6.17 \mathrm{Kg}$ \\
$\quad$ Appendix & 1 & \\
Operative time & 25 to $40 \mathrm{~min}$ \\
\hline
\end{tabular}




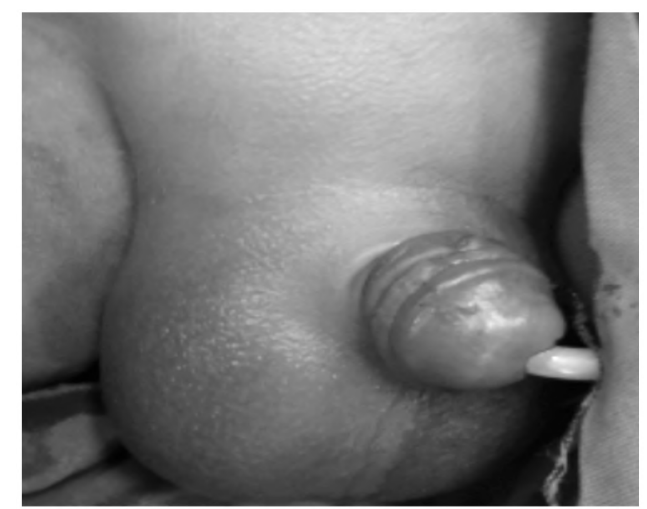

Fig. (1): Incarcerated Rt. congenital inguinal hernia.

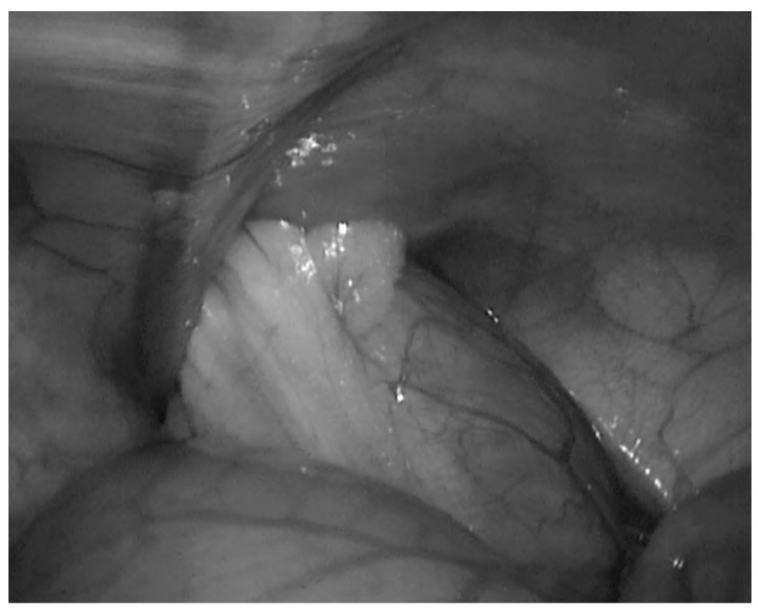

Fig. (3): Incarcerated bowel.

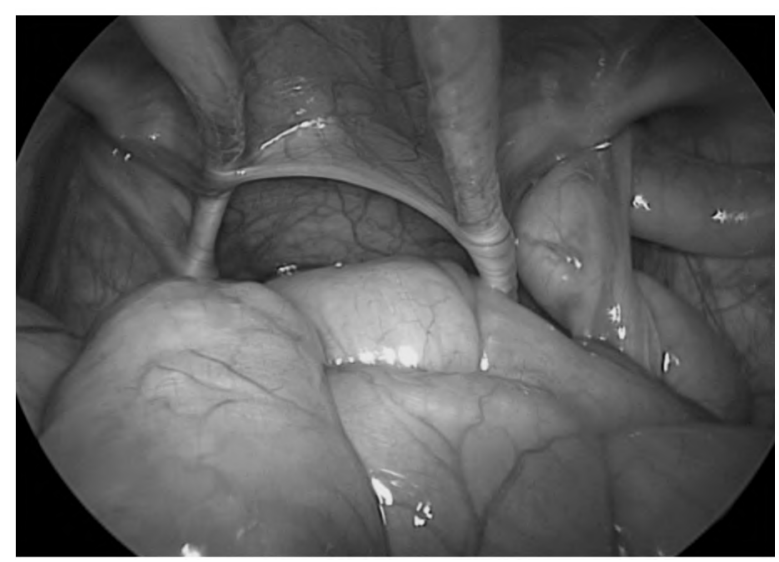

Fig. (5): Incarcerated appendix.

\section{Discussion}

Incarcerated congenital inguinal hernia is considered one of the most common pediatric surgical emergencies which need urgent surgical correction. Elective early conventional surgical repair is attempted after successful gentle manual reduction.

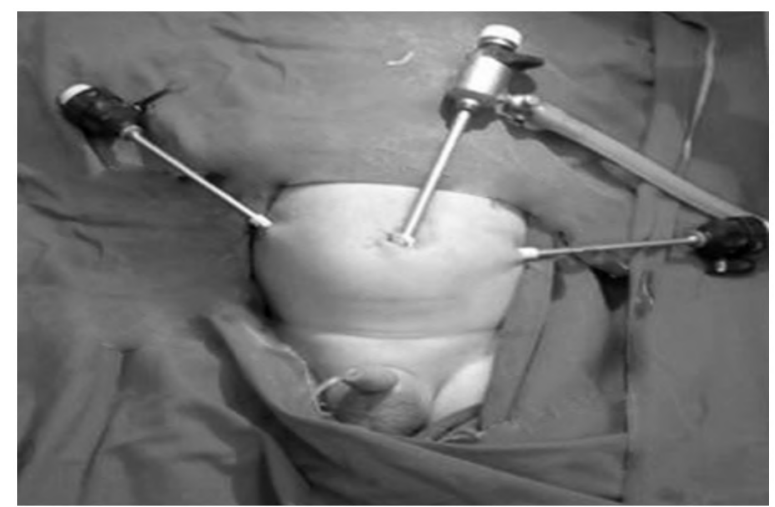

Fig. (2): Site of ports.

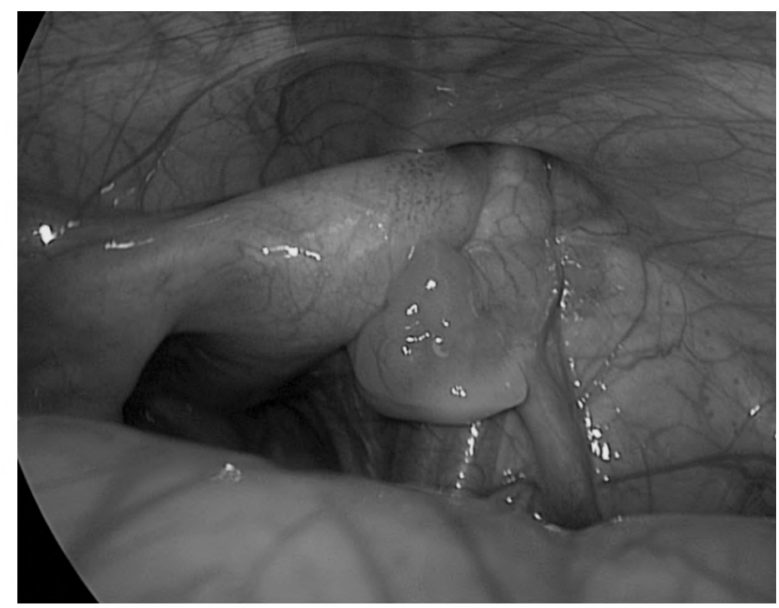

Fig. (4): Incarcerate ovary and fallopian tube.

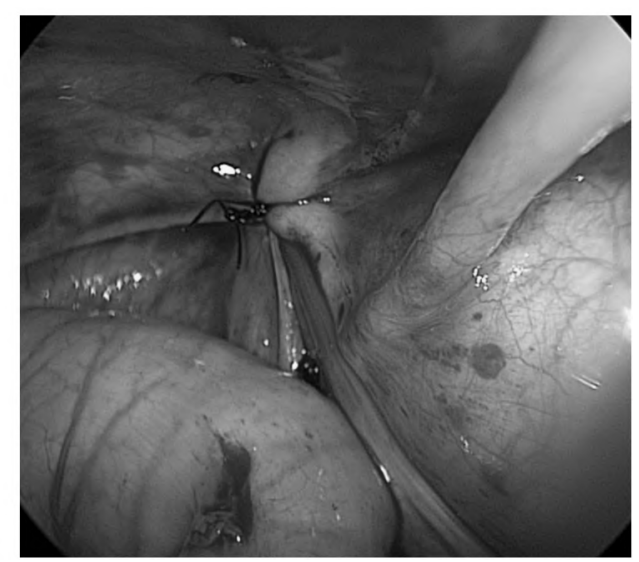

Fig. (6): Complete closure of the peritoneum at the internal ring.

If manual reduction failed, emergency surgery is required as early as possible [16]. The complication rate of emergency open inguinal herniotomy was higher than elective surgery $[\mathbf{1 7 , 1 8}]$. This may be due to the disturbed anatomy of the inguinal region and the edematous umbilical cord structure making the dissection in this area not devoid of risk, in 
addition to the difficulty in assessment of the irreducible contents especially if it was reduced during anesthesia or just before surgery.

Laparoscopic repair of pediatric inguinal hernia was gaining popularity because of the advantages of minimal invasive surgery like early recovery, less pain, improved cosmoses [19-21]. There are several reports on the use of laparoscopy in the management of incarcerated congenital inguinal hernia hernia [12,22]. Controversies are still present about the management of the successfully reduced incarcerated inguinal hernia. Most of the pediatric surgeons prefer to delay the repair within 3 days after reduction of the contents for fear of reincarceration and to allow the tissue edema to be resolved [22], other surgeons extend the delay for 7 days because they think that, incarceration is rare within that period $[\mathbf{1 4 , 1 5}]$. Few reports prefer immediate urgent operation even if the reduction was succeeded and we agree with that reports and all patients underwent emergency operation within 1.5 hour from its admission [12,13]

The use of laparoscopy in management of incarcerated congenital inguinal hernia has many advantages that confirm the safety and effectiveness of the procedures. The reduction of the contents was done under direct laparoscopic vision and so the reduced contents can be examined in the peritoneal cavity for signs of ischemia and the bowel loops can be irrigated by warm saline to improve the blood supply and relieve congestion and edema if present.

All case were reduced easily using traction method with manual external compression and this is confirmed by many other reports [12,23]. Zhou et al., experienced some difficulties in the reduction of contents and the anterolateral part of the internal inguinal ring was cut with scissors to assist reduction in two cases in his study [13]

Also from the advantages of laparoscopy; insufflation of the peritoneum by carbon dioxide widen and dilate the internal ring which facilitate reduction of the contents [22]. Kaya et al., reported that the edematous tissues and cord structures was bypassed and not touched during the laparoscopic repair and so alleviate the risk of injury of any structure. Chan et al., reported that the presence of fluid between the edematous peritoneum around the internal inguinal ring and the underlying structures actually provided a natural plain for dissection [23].

Laparoscopy is a useful tool in diagnosis and treatment of contralateral Patent Processus Vagi- nalis (PPV) and so it avoids the need for repeated anesthesia, and prevents a potentially hazardous incarceration of the contralateral side. Several reports demonstrated the role of laparoscopy in diagnosis and treatment of contralateral PPV [2427]. Two cases in this study were found to have a contralateral PPV which diagnosed pre-operatively by ultrasound and confirmed during laparoscopic exploration of the contralateral ring. Both cases were laparoscopically repaired at the same setting.

The mean operative time of laparoscopic repair of incarcerated inguinal hernia in unilateral cases ranged from 30 to 50 minutes in many reports $[\mathbf{1 3}$, 27,28 . In this study the operative time was ranged from 35 to 65 minutes with a mean 40 minutes calculated from the start of abdominal insufflation till the end of internal ring repair. Schier et al., reported that laparoscopic repair of incarcerated inguinal hernia with burse-string sutures of the peritoneum avoid dissection and risk of injury of the edematous cord structures and this lead to decrease in the time of surgery [29]. In this study, all cases were managed using burse-string sutures around the internal ring. Only one case was converted from laparoscopic to an open procedure after complete reduction of herniated contents due to bowel distention that obscured the field of vision and making the internal ring repair very difficult. All patients tolerated oral feeding 6 to 10 hours post-operatively and this was reflected on the length of hospital stay. Two patients suffered from abdominal distention as they underwent a difficult reduction after incarceration leading to bowel congestion which improved within 72 hours. No intraoperative complications were reported in this study such as hemorrhage, vascular and structural injuries. Similarly, many authors published similar series with no intraoperative complications [12, 28,30]. There was no recurrence of hernia in our study during the follow-up period which extended to 6 months. This zero recurrence rates were also documented in other studies $[\mathbf{1 2 , 2 2 , 3 1 ]}$

\section{Conclusion:}

Emergency laparoscopic repair of congenital inguinal hernia provide an alternative procedure in pediatric patients presenting with incarcerated hernia. It appears to be safe with few complications. It avoid the risk of dissection within the edematous inguinal structures, allow examination of the reduced contents under direct vision, help in diagnosis and repair of the contralateral patent processus vaginalis to avoid the risk of repeated operations. This was our initial experience in laparoscopic repair of incarcerated congenital hernia. The pro- 
cedure seems to be safe, feasible and effective but more cases with a longer period of follow-up are needed to confirm this results.

\section{References}

1- GALLEGOS N.C., DAWSON J., JARVIS M. and HOBSLEY M.: Risk of strangulation in groin hernias. Br. J. Surg., Oct., 78 (10): 1171-3, 1991.

2- KULAH B., KULACOGLU I.H., ORUC M.T., DUZGUN A.P., MORAN M., OZMEN M.M., et al.: Presentation and outcome of incarcerated external hernias in adults. Am. J. Surg., Feb., 181 (2): 101-4, 2001.

3- KURT N., ONCEL M., OZKAN Z. and BINGUL S.: Risk and outcome of bowel resection in patients with incarcerated groin hernias: Retrospective study. World J. Surg., Jun., 27 (6): 741-3, 2003.

4- DERICI H., UNALP H.R., NAZLI O., KAMER E., COSKUN M., TANSUG T., et al.: Prosthetic repair of incarcerated inguinal hernias: Is it a reliable method? Langenbecks Arch. Surg., Jun., 395 (5): 575-9, 2010.

5- LAU S.T., LEE Y.H. and CATY M.G.: Current management of hernias and hydroceles. Semin. Pediatr. Surg., Feb., 16 (1): 50-7, 2007.

6- RESCORLA F.J. and GROSFELD J.L.: Inguinal hernia repair in the perinatal period and early infancy: Clinical considerations. J. Pediatr. Surg., Dec., 19 (6): 832-7, 1984.

7- BAIRD R., GHOLOUM S., LABERGE J.M. and PULIGANDLA P.: Prematurity, not age at operation or incarceration, impacts complication rates of inguinal hernia repair. J. Pediatr. Surg., May, 46 (5): 908-11, 2011.

8- GHOLOUM S., BAIRD R., LABERGE J.M. and PULIGANDLA P.S.: Incarceration rates in pediatric inguinal hernia: Do not trust the coding. J. Pediatr. Surg., May, 45 (5): 1007-11, 2010.

9- TSAI Y.C., WU C.C. and YANG S.S.: Open versus minilaparoscopic herniorrhaphy for children: A prospective comparative trial with midterm follow-up evaluation. Surg. Endosc., Jan., 24 (1): 21-4, 2010.

10- ZAMAKHSHARY M., TO T., GUAN J. and LANGER J.C.: Risk of incarceration of inguinal hernia among infants and young children awaiting elective surgery. CMAJ, Nov. 4, 179 (10): 1001-5, 2008.

11- NAGRAJ S., SINHA S., GRANT H., LAKHOO K., HITCHCOCK R. and JOHNSON P.: The incidence of complications following primary inguinal herniotomy in babies weighing $5 \mathrm{~kg}$ or less. Pediatr. Surg. Int., Jun., 22 (6): 500-2, 2006.

12- SHALABY R., SHAMS A.M., MOHAMED S., ELLEATHY M., IBRAHEM M. and ALSAED G.: Twotrocar needlescopic approach to incarcerated inguinal hernia in children. J. Pediatr. Surg., Jul., 42 (7): 1259-62, 2007.

13- ZHOU H., MING S., MA L., WANG C., LIU X., ZHOU $\mathrm{X}$., et al.: Transumbilical single-incision laparoscopic versus conventional laparoscopic upper pole heminephroureterectomy for children with duplex kidney: A retrospective comparative study. Urology, Nov., 84 (5): 1199 204, 2014.
14- TIMMERS L., HAMMING J.F. and OOSTVOGEL H.J. [Non-incarcerated inguinal hernia in children: Operation within 7 days not necessary]. Ned. Tijdschr. Geneeskd., Jan. 29, 149 (5): 247-50, 2005.

15- GAHUKAMBLE D.B. and KHAMAGE A. S.: Early versus delayed repair of reduced incarcerated inguinal hernias in the pediatric population. J. Pediatr. Surg., Sep., 31 (9): 1218-20, 1996.

16- PHILIP L.G. and SCOTT C.: Boulanger. Inguinal Hernias and Hydroceles. In: Coran AG, editor. Pediatric Surgery. 7ed. Am: Elsevier; p. 986-7, 2012.

17- STEINAU G., TREUTNER K.H., FEEKEN G. and SCHUMPELICK V.: Recurrent inguinal hernias in infants and children. World J. Surg., Mar.-Apr., 19 (2): 303-6, 1995.

18- STYLIANOS S., JACIR N.N. and HARRIS B.H.: Incarceration of inguinal hernia in infants prior to elective repair. J. Pediatr. Surg., Apr., 28 (4): 582-3, 1993.

19- DUTTA S. and ALBANESE C.: Transcutaneous laparoscopic hernia repair in children: A prospective review of 275 hernia repairs with minimum 2-year follow-up. Surg. Endosc., Jan., 23 (1): 103-7, 2009.

20- ENDO M., WATANABE T., NAKANO M., YOSHIDA F. and UKIYAMA E.: Laparoscopic completely extraperitoneal repair of inguinal hernia in children: A singleinstitute experience with 1,257 repairs compared with cut-down herniorrhaphy. Surg. Endosc., Aug., 23 (8): 1706-12, 2009.

21- IKEDA H., HATANAKA M., SUZUKI M., FUJINO J., TAHARA K. and ISHIMARU Y.: A selective sac extraction method: Another minimally invasive procedure for inguinal hernia repair in children: A technical innovation with satisfactory surgical and cosmetic results. J. Pediatr. Surg., Aug., 44 (8): 1666-71, 2009.

22- KAYA M., HUCKSTEDT T. and SCHIER F.: Laparoscopic approach to incarcerated inguinal hernia in children. J. Pediatr. Surg., Mar., 41 (3): 567-9, 2009.

23- CHAN K.W., LEE K.H., TAM Y.H., SIHOE J.D., CHEUNG S.T. and MOU J.W.: Laparoscopic inguinal hernia repair by the hook method in emergency setting in children presenting with incarcerated inguinal hernia. J. Pediatr. Surg., Oct., 46 (10): 1970-3, 2011.

24- MISHRA P.K., BURNAND K., MINOCHA A., MATHUR A.B., KULKARNI M.S. and TSANG T.: Incarcerated inguinal hernia management in children: 'A comparison of the open and laparoscopic approach'. Pediatr. Surg. Int., Jun., 30 (6): 621-4, 2014.

25- SCHIER F.: Laparoscopic surgery of inguinal hernias in children-initial experience. J. Pediatr. Surg., Sep., 35 (9): 1331-5, 2000.

26- SCHIER F.: Direct inguinal hernias in children: Laparoscopic aspects. Pediatr. Surg. Int., 16 (8): 562-4, 2000.

27- NAH S.A., GIACOMELLO L. EATON S., De COPPI P., CURRY J.I., DRAKE D.P., et al.: Surgical repair of incarcerated inguinal hernia in children: Laparoscopic or open? Eur. J. Pediatr. Surg., Jan., 21 (1): 8-11, 2011.

28- ESPOSITO C., TURIAL S., ALICCHIO F., ENDERS J., CASTAGNETTI M., KRAUSE K., et al.: Laparoscopic repair of incarcerated inguinal hernia. A safe and effective 
procedure to adopt in children. Hernia, Apr., 17 (2): 2359, 2013.

29- SCHIER F.: Laparoscopic inguinal hernia repair-a prospective personal series of 542 children. J. Pediatr. Surg., Jun., 41 (6): 1081-4, 2006.

30- FERZLI G., SAYAD P. and NABAGIEZ J.: Needlescopic extraperitoneal repair of inguinal hernias. Surg. Endosc. Aug., 13 (8): 822-3, 1999.

31- KOIVUSALO A., PAKARINEN M.P. and RINTALA R.J.: Laparoscopic herniorrhaphy after manual reduction of incarcerated inguinal hernia. Surg. Endosc., Dec., 21 (12): 2147-9, 2007.

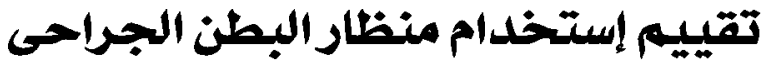

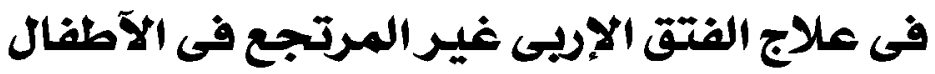

تطود منظار البطن الجراحى وآدى إلى تفيير الآنكار الجراحية لإصاح الفتق الإربى الغير مرتجع فى الآطفال فضلاً عن مساعدته فى إلى إلى

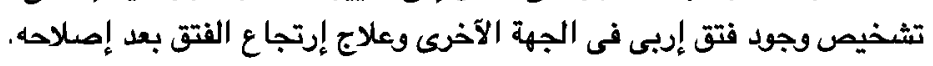

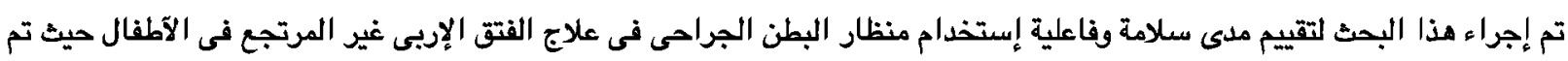

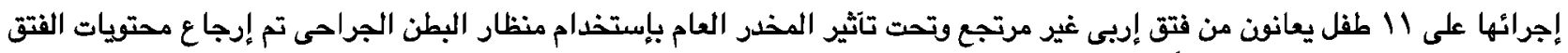

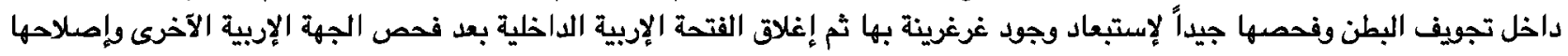
إن وجل بها فتق هى الآخرى.

ويعد إستخدام المنظار تبين آن له مميزات عديدة مثل إن الهواء المستخدم لنفخ البطن يساعد في توسيع الفتحة الإربية الداخلية مما يسهيل

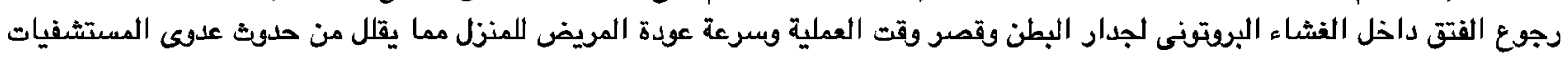

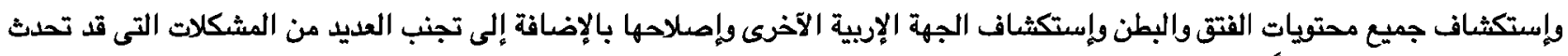

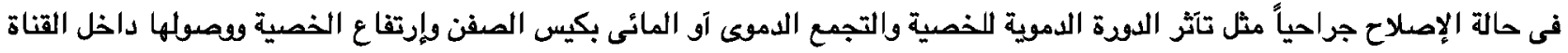
الإريية. 